\title{
Recent Innovations in Antenna Design for Wireless Sensor Networks
}

\author{
David V. Thiel and Amir Galehdar \\ Centre for Wireless Monitoring and Applications, \\ Griffith University, Nathan Qld 4111 Australia \\ d.thiel@griffith.edu.au
}

\begin{abstract}
Design parameters for an ideal wireless sensor network include minimal size and energy consumption, local intelligence for self-assembly and data processing, minimum data transmission over maximum range, ad hoc deployment and redundant path allocation. This paper reviews some of the recent developments in antenna design for wireless sensor networks.
\end{abstract}

Keywords: wireless sensor networks, antenna design, loss ground plane, bandwidth.

\section{INTRODUCTION}

Wireless sensor networks offer the possibility of a completely new perspective on a very broad range of fields. Monitoring becomes a three dimensional opportunity and fine detailed investigations of the environment and/or the system becomes possible. At Griffith University, inertial sensor technology is used to monitor the position of human limbs during sporting activities, and the location of players on a playing field. Two dimensional and three dimensional location of untethered sensors allows complete freedom of movement and biomechanical measurements can be made outside of the laboratory. This allows coaches to record and interpret data during a competition event and to observe patterns of play in team events. Other applications include the movement of elderly people, and injury recovery observations.

There has been significant interest in developing sensor systems that can be deployed ubiquitously in an ad-hoc (i.e. random) manner [1-3] or dynamic systems where the sensors are placed on or inside moving agents. Every stand-alone sensor must have the following parts:

1) A sensor surface or sensing mechanism

2) Sensor support electronics

3) A microcontroller for data acquisition, signal processing and data packaging

4) RF modem with antenna

5) Media to support the sensor

6) Time synchronization.

7) Energy source (energy storage or energy harvesting)

The system must be integrated into a single "wireless" unit. Encapsulation and/or enclosure technology also becomes an important part of the sensor units. In the case of mass manufacture, minimal environmental impact must be considered.
One major research thrust has been in the development of "smart dust" at the University of California at Berkeley, USA [4]. These devices have a size target of $1 \mathrm{~mm} \times 1 \mathrm{~mm} \times 1 \mathrm{~mm}$ and should include all the components shown in the list above.

A second major thrust has been the development of radio frequency identification (RFID) systems adapted for sensing [5]. In the case of passive RFID systems, the sensor is interrogated using a low frequency, higher powered radio signal. This provides sufficient power for the electronics to output a data stream usually at a much higher frequency (and so at a high data rate). It is projected that RFID will replace bar code scanning in shopping environments, manufacturing facilities and paper record systems (to name but a few potential applications) [6]. Manufactured on thin plastic sheeting with a single integrated silicon chip glued to a printed antenna, the technology is very susceptible to the effects of adjacent materials - both dielectric and conductive [7].

For many applications, however, the devices must be manipulated with human hands and so a slightly larger size is appropriate. This increased size provides the opportunity for larger antennas, sensor structures, increased energy storage and more powerful processing. In this paper, progress towards optimising these technologies is reported.

\section{Signal PATH THROUGH THE NETWORK}

The transmission link is usually the most significant drain on energy. In a large network (see Fig. 1), the passage of a data packet from one sensor, through many other nodes to the master node requires the intermediate nodes to be active (i.e. not in a sleep mode) and each node must receive and retransmit the information. For this reason, it is desirable to reduce the transmission data rates to a minimum through local processing to achieve data compression at each sensor node. In principle, given sufficient training, it is possible to reduce the transmission to a minimum by only communicating within threshold values as a single packet with the node number. Time delays through the system are greatly reduced, the possibility of packet collision near the master node is minimised and so the energy requirements are minimised.

Commonly each node will be programmed to wake up from sleep mode, take a reading, and transmit the data. If only out-of-range data is transmitted (that is, an abnormal reading is detected by the sensor), the master node must be routinely reassured that every node in the network is still functioning satisfactorily. 


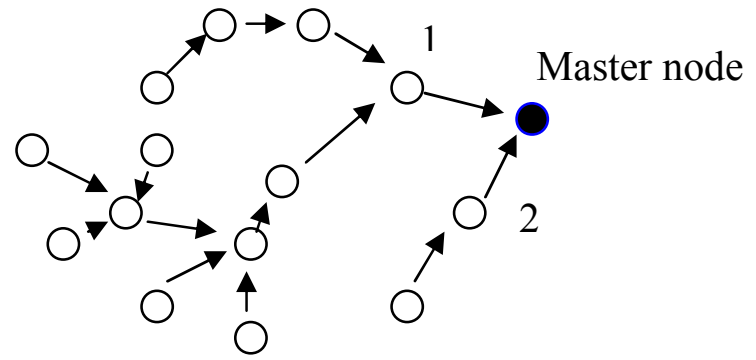

Fig 1: Sensor network routing path to the master node. Note that sensor 1 must carry data for 12 nodes and sensor 2 must carry data for 2 nodes.

\section{ENVIRONMENTAL CONSIDERATIONS}

There are two environmental considerations that must be addressed for wireless sensors. One relates to the impact on the environment of the manufacturing process and the disposal of the sensors at end-of-life. The second relates to the problem of have sensing surfaces exposed to the environment while the support electronics and communications system is protected from the environment. These are discussed in turn.

\section{A. Environmental Impact}

Recent directives in the European Community (EC) address the manufacture of electronic devices. These directives apply to all electronics goods manufactured in Europe and consequentially the directives have impacted on all electronics manufacture worldwide.

The Reduction of Hazardous Substances directive (RoHS) requires manufacturers to minimise the use of polluting (i.e. toxic) materials such as lead (mainly found in solder), and some fire retardants (found in printed circuit boards) [8]. Electronic components from suppliers often come with RoHS complaint certificates and non-compliant components are slowly being removed from the inventory. Lead-free solder has a higher transition temperature. Alternative technologies to replace soldering include the use of conductive adhesives and thermal bonding.

The EC directive on Waste from Electrical and Electronic Equipment (WEEE) now constrains all manufactures to take back and recycle up to $80 \%$ of the materials used in the initial manufactured goods [9]. Design for recycling is now an additional design requirement for all electronics manufacture.

\section{B. Environmental Protection}

The design approach to locating sensor surfaces with access to the environment and still protecting the electronics has been a major problem in wireless sensor technology. The techniques in common use include epoxy dots, complex enclosure structures and cabling. Plastic substrates are proving to be a useful method of both circuit construction [10] and sensor surface production [11]. This has been facilitated by significant improvements in fabrication technologies using conductive polymers [11].

\section{ANTENNA DESIGN}

Significant attention has been directed towards the optimisation of antenna structures for maximum gain, minimal size and minimum consumables $[12,13]$. In particular multiobjective optimisation routines allow decisions to be made in relation to such vital parameters as the input impedance, bandwidth and gain for a fixed surface area. Planar (i.e. two dimensional) antenna structures on thin substrates are subjected to bending, and the change in the resonant frequency often with a very a narrow bandwidth, means that a curved antenna may be resonant out of band with a subsequent loss in link budget [14]. Bandwidth broadening strategies such as $U$ shaped slots in the patch can be used to accommodate even the tightest bend [14].

Another possible design employs the use of switchable parasitic antennas to direct the beam to maximize the network communications links when, for example, planar antennas are located on the conductive walls in a room [15]. The switching mechanisms currently used are not particularly reliable, and the use of RF MEM's switches is highly desirable [16]. MIMO antenna systems have also been considered but there are size and computational penalties associated with this technology.

The effect of the support material on a $2 \mathrm{D}$ meander line antenna has been examined using numerical modelling. Fig 2 shows the change in resonant frequency and the change in bandwidth when the antenna is placed in close proximity to a lossy dielectric half space. Note that the free space resonant frequency decreased by $25 \%$ when a dielectric material without loss is close by, and this decrease chnages to almost $50 \%$ when the substrate has significant loss. This is a major difficulty if the sensors are located randomly or can be moved.

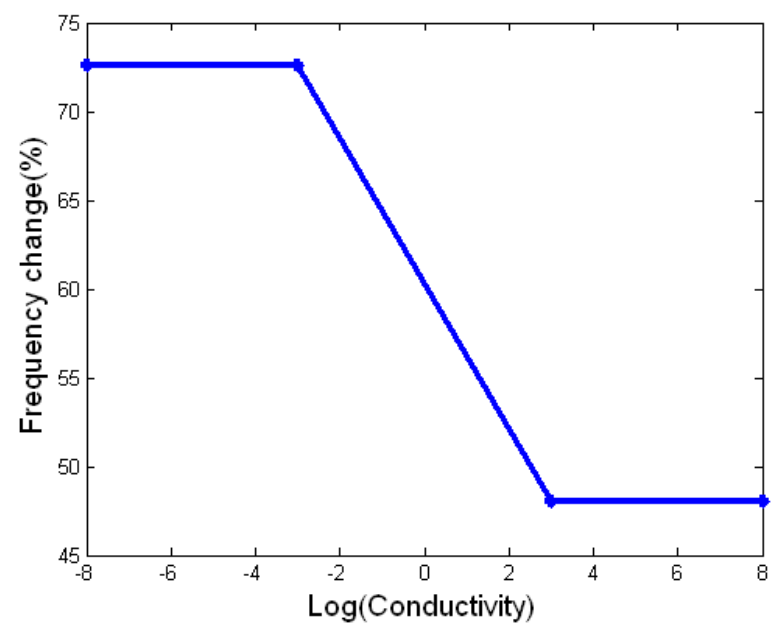

Fig 2. Percentage change in the resonant frequency of a meander line antenna close to a substrate with various conductivity.

In the case of a straight wire dipole, the resonant frequency is decreased and the bandwidth increases as the wire diameter increases. In the case of the meander line antenna close to a conductive half space, both the resonant frequency and the bandwidth increases (see Fig 3). The increase in bandwidth is slight and can not compensate for the change in resonant frequency. There is a requirement to increase the bandwidth significantly or to reduce the effect of the ground plane. 


\section{ACKNOWLEDGMENTS}

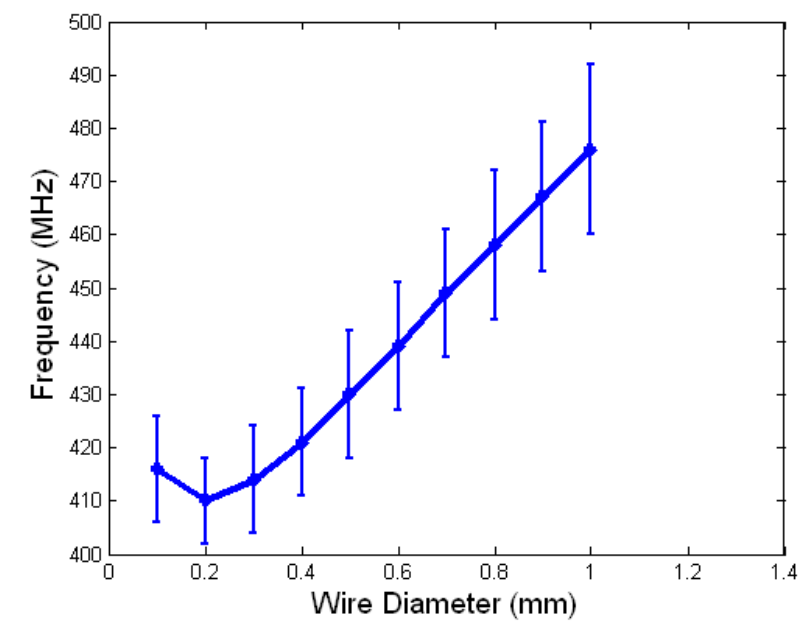

Fig 3. Change in resonant frequency of a meander line antenna close to a highly conductive ground plane as the wire diameter is increased. The resonant frequency in free space is $869 \mathrm{MHz}$

\section{A. 3D antenna structure}

A new method of planar antenna design using multiple layers in a meander line configuration was recently reported [17]. This antenna structure has improved immunity from the effect of the ground plane. The fabrication of such antennas requires multiple lamination. The antenna remains essentially planar, but is less flexible than the printed 2D antennas commonly used. The 3D design technique also allows the total area to be smaller while maintaining the efficiency.

\section{B. Environmental Impact}

At present, most plastic recycling world-wide divides the sold waste stream into rigid plastic and plastic film. Commonly the plastic film is incinerated (sometimes as an additional fuel for thermal power generation) while the rigid plastic is recycled. The presence of conducting material in a 3D laminated antenna implies that these antennas will be incinerated. The choice of conductor becomes a major issue in reducing pollution [18].

\section{CONCLUSIONS}

The field of wireless sensor networks is an exciting and rapidly growing field of research. While not discussed in any detail, applications for wireless sensor networks span all parts of human activity. As outlined in the paper, there are many new design challenges for circuit designers, sensor systems and antenna engineers. Circuit and system optimization must now include a multitude of factors which not only address sensor node size, efficiency and energy requirements, but also the environmental and packaging aspects of the design and fabrication. This paper has not addressed the issues of data processing and the use of actuators in control systems. These factors also play a significant part in the final design of the sensor network. The references given in this paper are a very small part of the literature available in this field.
Much of the work reported hare has been undertaken within the Centre for Wireless Monitoring and Applications by Michael Maggs, Elyas Palantei, Steven O'Keefe, Daniel James, and Neeli Madhusudan Rao. The author is particularly indebted to all members of the Centre who has strongly supported this work.

\section{REFERENCES}

[1]. M.C-Y. Chong, and S.P. Kumar, "Sensor networks: evolution, opportunities, and challenges," Proc IEEE vol. 91 (8), pp 1247-1256, Aug. 2003.

[2]. Estrin, L. Girod, G. Pottie and M. Srivastava, "Instrumenting the world with wireless sensor networks", Proc ICASSP'01, vol. 4, pp 2033-2036, 2001.

[3]. I.F. Akyildiz, W. Su., Y. Sankarasubramaniam, and E. Cayirci, "Wireless senor networks: a survey", Computer Networks, vol. 38, pp. 393-422, 2002.

[4]. J. M. Kahn, R.H. Katz and K.S.J. Pister, "Next century challenges: mobile networking for 'smart dust", Proc. $5^{\text {th }}$ ACM/IEEE Int. Conf. on mobile Computing and Networking, Seattle, WA, USA. pp 271-278, 1999.

[5]. R. Want, "Enabling ubiquitous sensing with RFID", Computer, vol. 37 (4), pp. 84-86, April 2004.

[6]. B. Nath, F. Reynolds, and R. Want, "RFID technology and applications", IEEE Pervasive Computing, vol. 5, (1), pp 22-24, Jan-Mar., 2006.

[7]. K.V.S. Rao, P.V., Nikitin, and S.F. Lam, "Antenna design for UHF RHID tags: a review and a practical application", IEEE Trans. Antennas and Propagation vol. 53 (12), pp 3870-3876, Dec. 2005.

[8]. Europa, "Directive 2002/95/EC of the European Parliament and of the Council of 27 January 2003 on the restriction of the use of certain hazardous substances in electrical and electronic equipment," Official Journal L 03, 13/02/2003 P. 0019-0023.

[9]. Europa, "Directive 2002/96/EC of the European Parliament and of the Council of 27 January 2003 on waste electrical and electronic equipment (WEEE) - Joint declaration of the European Parliament, the Council and the Commission relating to Article 9" Official Journal L 037, 13/02/2003 P. 0024 - 0039.

[10]. D.V. Thiel, and M.R. Neeli, "Fabrication of electronic components in plastic, Australian Patent number 2005903514, PCT/AU06/000926, July 2006.

[11]. J. Janata, and M. Josowitz, "Conducting polymers in electronic chemical sensors," Nature Material, vol. 2, pp;. 19-24,

[12]. M. Randall, A. Lewis, A. Galehdar, and D.V. Thiel, "Using ant colony optimization to improve the efficiency of small meander line RFID antennas," IEEE Int. Conf. e-Science and Grid Computing, pp. 345-351, Dec 2007.

[13]. Galehdar, D.V. Thiel and S.G. O'Keefe, "Tapered wire antenna design for maximum efficiency and minimal environmental impact," ISAPE'08, Kunming, China, pp. 23-26, Nov. 2008.

[14]. Galehdar and D.V. Thiel, "Flexible, light-weight antenna at $2.4 \mathrm{GHz}$ for athlete clothing," IEEE Int. Symp. Antennas and Propagation, pp. 41604163, June 2007.

[15]. D.V. Thiel and P. Lisner, "Sensor networks and microsystems: get smarter!" Proc SPIE vol. 5649, p. 354, DOI:10.1117/12.58, 354, 2005.

[16]. Palantei, and D.V. Thiel, "The impact of bias voltage on the performance of a p.i.n. diode loaded smart antenna," J. Japan Society of Applied Electromagnetics, vol. 15, (3), pp 274-277, 2007.

[17]. Galehdar, D.V. Thiel and S.G. O'Keefe, "Design methods for 3D RFID antennas located on a conducting ground plane," IEEE Trans. Ant \& Prop, vol 57 (2), pp 339-346, Feb. 2009.

[18]. D.V. Thiel, "Sustainable electronics: wireless systems with minimal environmental impact," ISAPE'08 Kunming, China, pp 1298-1301, Nov 2008 . 